\begin{tabular}{|c|c|c|}
\hline $\begin{array}{l}\text { PKS } \\
\text { PUBLIC } \\
\text { KNOWLEDGE } \\
\text { PROJECT }\end{array}$ & $\begin{array}{c}\text { REVISTA DE GEOGRAFIA } \\
\text { (RECIFE) } \\
\text { http://www.revista.ufpe.br/revistageografia }\end{array}$ & $\begin{array}{l}\text { OJS } \\
\frac{\text { OJEN }}{\text { OPENAL }} \\
\text { SYSTEMS }\end{array}$ \\
\hline
\end{tabular}

\title{
POVO XUKURU DO ORORUBÁ: LUTAS, RESISTÊNCIAS E INSURGÊNCIAS NO ESPAÇO AGRÁRIO PERNAMBUCANO
}

\author{
Bruna Maria da Silva Rapozo ${ }^{1}$, Maria Rosana da Costa Oliveira ${ }^{2}$
}

${ }^{1}$ Doutoranda do Programa de Pós-Graduação em Geografia da UFPE. brunnarapozo@gmail.com
${ }^{2}$ Doutoranda do Programa de Pós-Graduação em Geografia da UFPE. rosanaoliveira87@gmail.com

Artigo recebido em 03/05/2018 e aceito em 02/11/2018

\begin{abstract}
RESUMO
Este artigo fazer uma reflexão sobre comunidades e povos tradicionais diante dos conflitos fundiários que ocorreram em muitas terras indígenas e região do país, bem como os conflitos e violência contra os povos indígenas no estado de Pernambuco. Nesse sentido buscou-se trazer para o debate a realidade do povo Xukuru do Ororubá, Pesqueira - PE, o qual, desde o período colonial, vem lutando para manter suas terras, identidade e territórios. Para realização do estudo foi utilizadas Substituir por pesquisas documentais com documentos da Fundação Nacional do Índio (FUNAI) e Conselho Indigenista Missionário Indigenista (CIMI), além de pesquisa bibliográfica referente à temática central da reflexão. Também foram utilizadas informações obtidas em encontro de povos tradicionais, grupo de estudos e pesquisa sobre a questão agrária, e temáticas referentes ao espaço agrário, comunidades e tradicionais, entre outros.
\end{abstract}

Palavras-chave: Comunidade tradicional, Terra indígena, Conflito agrário.

\section{XUKURU PEOPLE OF ORORUBÁ: STRUGGLES, RESISTANCE AND INSURGENCIES IN AGRARIAN SPACE PERNAMBUCANO}

\begin{abstract}
This article make a reflection on traditional communities and peoples before land conflicts that occurred in many indigenous lands and region of the country, as well as the conflicts and violence against indigenous peoples in the State of Pernambuco. There are still conflicts and violence against the native people. Accordingly sought to bring to the debate the reality of the people Xukuru of Ororubá, Pesqueira -PE, which, since the colonial period, has been struggling to maintain their land, identity and territory. For conducting the study was used to replace by documentary research with documents from the National Indian Foundation (FUNAI) and Indigenous Indigenous Missionary Council (CIMI), in addition to bibliographical research on the central theme of reflection, were also used information obtained in meeting of traditional peoples, group of studies and research on the agrarian question, and agricultural space-related themes, and traditional communities, among others.

Keywords: Traditional communities, Indigenous land, Agrarian conflict.
\end{abstract}




\section{INTRODUÇÃO}

"Nós não temos a terra como um objeto de especulação. A gente sabe que quando Deus criou a terra, Ele não criou para ninguém fazer da terra um comércio. Então se nós dependêssemos unicamente dos parlamentares brasileiros, então, dos índios do Brasil, não existiria mais nenhum, o resto já tinha sido todo morto queimado, assim como queimaram Galdino” (Cacique Xicão 1950-1998).

O objetivo central deste texto é fazer uma reflexão sobre comunidades e povos tradicionais diante dos conflitos fundiários que vem ocorrendo desde o período colonial, em muitas terras indígenas da região Nordeste, bem como em outras regiões do país, onde ainda existem conflitos e violência contra os povos tradicionais. Um exemplo de povo indígena do Nordeste é o caso do Povo Xukuru do Ororubá, de Pesqueira - PE, que vem lutando para manter suas terras, identidade e territórios. O território Xukuru está localizado entre o Agreste e o Sertão Pernambucano, conforme o mapa a seguir (mapa 1).

Figura 1: Território Xukuru do Ororubá, de Pesqueira - PE
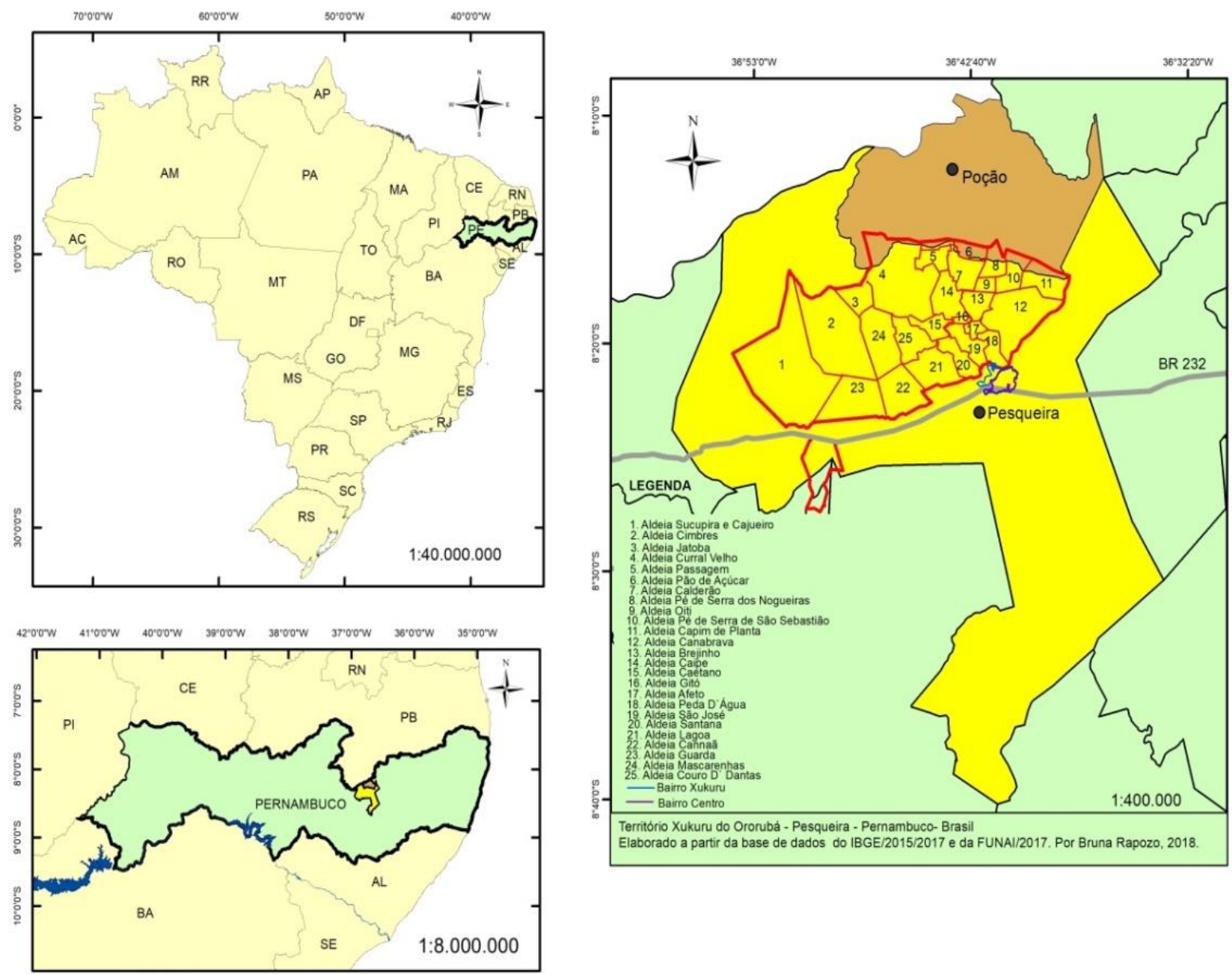

Fonte: Elaborado a partir da base de dados do IBGE/2015/2017 e da FUNAI/2017. Por Bruna Rapozo, 2018. 
A Serra de Ororubá está localizada, no Semiárido pernambucano e delimita as bacias do São Francisco e do Ipojuca. A serra é caracterizada por uma vegetação formada pelos biomas da Caatinga e brejo de altitude, resquícios de mata atlântica e pelos rios intermitentes (SILVA, 2007a). A população indígena contabilizada pela FUNASA, em 2010, foi de 10.536 indivíduos vivendo na área demarcada. Além desses, o mesmo órgão contabilizou cerca de 200 famílias morando na zona urbana da cidade de Pesqueira.

Com relação às comunidades tradicionais, no Brasil há uma diversidade que lutam para permanecerem na terra e reproduzirem sua identidade, cultura e modo de vida e singularidades. Esse modo de vida é respaldado nas normativas dos Direitos Humanos e na Constituição Federal Brasileira, com leis e decretos específicos que buscam garantir a proteção das terras e identidade étnica dos povos e comunidades tradicionais no território nacional.

No entanto, e de acordo com Little (2003), até recentemente, a diversidade fundiária do Brasil foi pouco conhecida no país e, mais ainda, pouco reconhecida oficialmente pelo Estado brasileiro. A partir da Constituição Federal de 1988, os povos e terras tradicionalmentes ocupadas foram reconhecidas e demandaram outras formas de regulamentações fundiárias que contemplassem o modo de vida e identidade territorial dos povos e comunidades tradicionais, cuja vida está diretamente relacionada às florestas, matas, ecossistema (águas, terra) e território.

Além disso, Little (2003) salienta que os territórios dos povos tradicionais fundamentam-se em décadas, em alguns casos, séculos de ocupação efetiva. A longa duração dessa ocupação fornece um peso histórico às suas reivindicações territoriais. Quanto às categorias povos e comunidades tradicionais, de acordo com os estudos de Carneiro da Cunha; Almeida (2001), "essas categorias possui (sic) um primeiro marco histórico de constituição de vinculação do "tradicional" a determinados segmentos populacionais ligandoos às ideias de entrave ao desenvolvimento". As comunidades e povos tradicionais são vistos como obstáculos ao processo de expansão dos empreendimentos do modo de produção capitalista-colonial, uma vez que essas populações utilizam os bens naturais, terra, rios, florestas, plantas etc. como principais fontes de vida e de construção dos seus conhecimentos, tradições e modo de vida.

A construção dos conhecimentos tem vasta relação com o ambiente físico e social habitado por estas populações (SCHMIDT, 2001, p. 73), esse conhecimento é constituído por um "conjunto de saberes e saber-fazer a respeito do mundo natural e sobrenatural, transmitido 
oralmente, de geração em geração" (DIEGUES, 2001, p. 31). Os povos e comunidades tradicionais tem importante papel na conservação dos ecossistemas, biodiversidade e reprodução dos conhecimentos milenares sobre os agroecossistemas, diversidade genética e remédios fitoterápicos. No entanto, essas comunidades e povos sofrem constantes ameaças de expropriação dos seus territórios por parte dos grupos econômicos e grandes projetos, muitas vezes com a legitimação e apoio do Estado.

A compreensão dos conflitos por terra, água e território envolvendo as comunidades e povos tradicionais serão possíveis através dos conceitos de território e territorialidade, como serão mais bem observados a seguir.

Para Filho e Mendes (2014):

Estão sendo considerados "povos e comunidades tradicionais" no Brasil os povos indígenas, as comunidades remanescentes de quilombos, os pescadores artesanais, os ribeirinhos, os povos ciganos, os povos de terreiro, os pantaneiros (do pantanal mato-grossense e sul-mato-grossense), os faxinalenses do Paraná e região (que consorciam o plantio da erva-mate com a suinocultura e com o extrativismo do pião a partir do uso comum do território), as comunidades de fundos de pasto da Bahia (que praticam a caprinocultura em territórios de uso comum), os caiçaras (pescadores artesanais marítimos dos estados de São Paulo, Rio de Janeiro e Espírito Santo, que consorciam a pesca artesanal e extrativismo em áreas comuns com o cultivo), os geraizeiros (que exercem ocupação tradicional dos gerais ou Cerrado), os apanhadores de flores sempre-vivas (que tradicionalmente exerciam o extrativismo em áreas de uso comum nas campinas, hoje cercadas em grande medida pela monocultura do eucalipto e pela criação de unidades de conservação de proteção integral), entre outros que, somados, representam parcela significativa da população brasileira e ocupam parte considerável do território nacional (FILHO \& MENDES, 2014. p. 15).

Para Diegues, "um dos critérios mais importantes para definição de culturas ou populações tradicionais, além do modo de vida, é, sem dúvida, o reconhecer-se como pertencente àquele grupo social particular" (DIEGUES, 2000, p. 84). Na concepção de Carlos Rodrigues Brandão, o conceito de comunidades tradicionais está relacionado com vários ecossistemas, tempos e espaços, visto que os saberes e conhecimentos são construídos de forma coletiva e passados entre as gerações.

Comunidade tradicional constitui-se como um grupo social local que desenvolve: a) dinâmicas temporais de vinculação a um espaço físico que se torna território coletivo pela transformação da natureza por meio do trabalho de seus fundadores que nele se instalaram; b) saber peculiar, resultante das múltiplas formas de relações integradas à natureza, constituído por conhecimentos, inovações e práticas gerados e transmitidos pela tradição ou pela interface com as dinâmicas da sociedade envolvente; c) uma relativa autonomia para a reprodução de seus membros e da coletividade como uma totalidade social articulada com o "mundo de fora", ainda que quase invisíveis; d) o reconhecimento de si como uma comunidade presente herdeira de nomes, tradições, lugares socializados, direitos de posse e proveito de um território ancestral; e) a atualização pela memória da historicidade de lutas e de 
resistências no passado e no presente para permanecerem no território ancestral; f) a experiência da vida em um território cercado e/ou ameaçado; g) estratégias atuais de acesso a direitos, a mercados de bens menos periféricos e à conservação ambiental. (BRANDÃO, 2010, p. 37)

O Decreto 6.040, de 7 de fevereiro de 2007, que institui a Política Nacional de Desenvolvimento Sustentável dos Povos e Comunidades Tradicionais, define os povos e comunidades tradicionais como:

Grupos culturalmente diferenciados e que se reconhecem como tais, que possuem formas próprias de organização social, que ocupam e usam territórios e recursos naturais como condição para sua reprodução cultural, social, religiosa, ancestral e econômica, utilizando conhecimentos, inovações e práticas gerados e transmitidos pela tradição (Decreto 6.040 , art. $3^{\circ}, \S 1^{\circ}$ )

Esses grupos possuem uma forte interação com a natureza, terra e bens naturais que representam a ancestralidade, a identidade, saberes e modo de vida que são passados de geração para geração através da cultura. Assim, institucionalmente foram criadas normativas jurídicas para apoiar e reconhecer os direitos dessa população.

No cenário jurídico internacional a luta destes povos foi reconhecida através da Convenção sobre a Diversidade Biológica (CDB) e da Agenda 21, na Conferência do Rio de Janeiro de 1992 (ECO/92), e pela criação, também em 1992, do Centro Nacional de Desenvolvimento Sustentado das Populações Tradicionais (CNPT), no âmbito do Instituto Brasileiro de Meio Ambiente e Recursos Naturais Renováveis (IBAMA). No ano de 2000 a implantação do Sistema Nacional de Unidades de Conservação (SNUC - Lei 9.985/2000) veio somar à luta pela conservação dos territórios das comunidades tradicionais, visto que suas atividades socioeconômicas são baseadas nas trocas ecológicas e por atividades extrativistas, caça, pesca plantio e criação.

De acordo com Toledo (2001) existem mais de 300 milhões de pessoas pertencentes a povos e comunidades tradicionais, vivendo em 75 dos 184 países do mundo, ocupando praticamente cada um dos principais biomas do planeta. No Brasil, existem atualmente cerca de 6 milhões de pessoas que compõem as comunidades tradicionais, destacando-se os indígenas, quilombolas, fundo e fecho de pasto, caiçaras, extrativistas, pescadores, ribeirinhos, etc. (CPT, 2014).

A identidade, tradição e reprodução social, político e econômica dos povos e comunidades tradicionais são constituídos a partir do seu território material e imaterial. Epistemologicamente, a palavra território, territorium em latim, é derivada diretamente do vocábulo latino terra, e era utilizado pelo sistema jurídico romano dentro do chamado jus 
terrendi (no Digeste, do século VI (HAESBAERT, 2004, p. 43). O conceito território é definido, quase sempre, a partir de relações de poder referentes à dominação e apropriação de uma área ou recursos por determinados atores ou grupos sociais que vão agregar concepção teórica e política ao conceito a partir das diferentes abordagens e ciências humanas. Território, assim, em qualquer acepção, tem a ver com poder, mas não apenas ao tradicional "poder político. Ele diz respeito tanto ao poder no sentido território e multiterritorialidade: um debate mais explícito, de dominação, quanto ao poder no sentido mais implícito ou simbólico, de apropriação (HAESBAERT, 2007).

Para Milton Santos (1999) o território em si não é conceito, ele só se torna conceito quando o consideramos na perspectiva do seu uso. Nesse sentido, para o autor, o território usado constitui como um todo complexo onde se tece uma trama de relações complementares e conflitantes. Milton Santos considera o território como:

\footnotetext{
Arena da oposição entre o mercado - que singulariza - com as técnicas da produção, a organização da produção, a geografia da produção e a sociedade civil - que generaliza - e desse modo envolve, sem distinção, todas as pessoas. Com a presente democracia de mercado, o território é suporte de redes que transportam as verticalidades, isto é, regras e normas egoístas e utilitárias (do ponto de vista dos atores hegemônicos), enquanto as horizontalidades levam em conta a totalidade dos atores e das ações (SANTOS, 1996, p. 207).
}

Na concepção de Milton Santos, o território constitui o traço de união entre o passado e o futuro imediato. Ele é visto como um campo de forças, como o lugar do exercício, de dialéticas e contradições entre o vertical e o horizontal, entre o Estado e o mercado, entre o uso econômico e o uso social dos recursos. Heaesbaert (2004) aponta que existem três principais leituras sobre território na Geografia. Entre elas, a leitura política (referente às relações espaço-poder), cultural (que prioriza a dimensão simbólica e mais subjetiva) e econômica (como fonte de recurso). No entender de Raffestin (1993) o território não poderia ser nada mais que o produto dos atores sociais. São eles que produzem o território, partindo da realidade inicial dada, que é o espaço. Há portanto um "processo" do território, quando se manifestam todas as espécies de relações de poder [...].

Já na abordagem teórico-metodológica de Saquet (2003) o território é compreendido através de dimensões que compreendem a historicidade e conflitualidade da esfera social, incorporando assim, o tempo, o espaço e o território, mais os aspectos econômicos, políticos e culturais.

Nessa perspectiva, de acordo com Saquet (2003): 
O território se dá quando se manifesta e exerce-se qualquer tipo de poder, de relações sociais. São as relações que dão o concreto ao abstrato, são as relações que consubstanciam o poder. Toda relação social, econômica, política e cultural é marcada pelo poder, porque são relações que os homens mantêm entre si nos diferentes conflitos diários (SAQUET, 2003, p. 24).

Para os povos e comunidades tradicionais, como é o caso, por exemplo, dos indígenas, o território é de suma importância para a reprodução das condições matérias e simbólicas da vida, cultura e ancestralidade, quase sempre é baseada em relações de solidariedade e valores comunitárias De acordo com Silva (2017b), a percepção do indígena sobre a terra, água, alimentos e vida, como é o caso da caso a comunidade Xukuru de Ororubá, ultrapassa o propósito comercial, sendo o seu território um espaço sagrado, em que a agricultura se torna um ritual, uma reprodução da vida ao fornecer medicamentos de cura e alimentação. Esta é uma herança transmitida para as novas gerações através da educação e um espaço de resistência e constante ressignificação da identidade.

Heaesbaert (2007) argumenta que se o território é uma construção histórica, sem esquecer que dele fazem parte diferentes formas de apropriação e domínio da natureza, as territorialidades também são forjadas socialmente ao longo do tempo, em um processo de relativo enraizamento espacial. Territorialidades que podem ser observadas no território do povo Xukuru através das suas práticas sociais como o uso comum das terras e bens naturais, como também nos rituais sagrados. Quanto à territorialidade ela é "a maneira pela qual as sociedades se satisfazem num determinado momento, para um local, uma carga demográfica e um conjunto de instrumentos também determinados, suas necessidades em energia e informação" (RAFFESTIN, 1993. p. 153). De acordo com Raffestin os atores ao se apropriarem dos espaços acabam por "territorializar" os mesmos, sustentados por um conjunto de ações, posturas, práticas, comportamentos, enfim códigos que revelam relações de poder [...].

O território não é só um espaço de tensão e conflitos políticos territoriais, ele é o lócus da manifestação de cultura, identidade e vida de um povo, havendo assim múltiplas e complexas relações de poder. Na compreensão de Oliveira (2004) o território representa a dimensão chave para a compreensão de como os povos indígenas se incorporam dentro do Estado-nação. Para o autor seria a partir da imputação a um grupo de uma base territorial fixa que teríamos o ponto de partida para compreendermos as mudanças passadas pelo povo, que afetariam tanto o funcionamento das instituições da sociedade étnica quanto a significação de suas manifestações culturais (Oliveira 2004, p. 22-3). 


\section{POVO XUKURU DO ORORUBÁ}

Diante da conjuntura política que se estabeleceu no Brasil pós-golpe parlamentar de 2016, com o aumento expressivo de chacinas, conflitos socioambientais, desmonte de direitos e a ameaça de instituição de um marco temporal ${ }^{1}$, é relevante discutir, sob o prisma geográfico, a temática indígena. Trazemos para ilustrar o debate, especificamente, a etnia Xukuru de Ororubá, do estado de Pernambuco. Essa etnia tem processos particulares, mas que são semelhantes com conflitos presentes em várias etnias do Brasil, principalmente quando se trata de tensões e conflitos referentes à posse da terra.

Historicamente as comunidades e povos tradicionais foram marginalizados, perseguidos e expulsos de suas terras e territórios, sendo invisibilizados enquanto sujeitos históricos, quando não considerados extintos. Nesta região os índios eram chamados de caboclos, para Silva (2008) se tratava de populações marginais, espoliadas, pensadas como totalmente aculturadas, quando situadas em uma escala evolucionista, comparadas com os grupos indígenas do Norte do Brasil, portadores de uma legítima e suposta pureza cultural originária.

Com relação os indígenas do Nordeste, como os Xukurus, por exemplo, Silva (2011) destaca que:

[...] pensar os índios no Nordeste é, antes de tudo, conhecer os processos históricos e os fluxos culturais expressos nas relações com diferentes atores sociais pertinentes a cada grupo indígena. A cultura é vista não mais por uma perspectiva das perdas, e sim como expressão das relações sociais e históricas de diferentes atores em interação, local e globalmente, das disputas por terras às várias influências políticas, no âmbito público ou, mais proximamente, nas articulações, alianças e organizações sociais (SILVA, 2011, p. 495).

Tradicionais moradores do antigo aldeamento de Cimbres - oficialmente extinto no final do século XIX (SILVA, 2007a), sempre tiveram uma relação muito forte com a terra onde vivem desde tempos coloniais. De acordo com Andrade (2005), a colonização europeia no Sertão e Agreste só veio ganhar impulso em meados do século XVII, visto que até então, a Zona da Mata era o território utilizado para a plantação da valorizada monocultura da cana de açúcar.

Com o avanço continuado do gado no Agreste e o aumento gradativo da população colonizadora no local ainda no século XVII, a política catequizadora e expansionista portuguesa optou por aldear os índios da região. Muitas famílias pobres, inclusive indígenas,

\footnotetext{
${ }^{1}$ Tem sido o chamado marco temporal, uma tese político-jurídica inconstitucional, segundo a qual os povos indígenas só teriam direito às terras que estavam sob sua posse em 5 de outubro de 1988 (CIMI, 2017). Rapozo e Oliveira, $2018 \quad$ ISSN 0104-5490 161
} 
passaram a trabalhar para os fazendeiros invasores em troca de pequenas glebas de terra (os chamados "sítios") onde cultivavam alimentos para subsistência. A partir de 1750, a cultura algodoeira também incluiu os indígenas no processo produtivo.

Seguindo a dinâmica da economia brasileira do final do século XIX e início do XX, a floresta foi destruída para dar lugar aos grandes cafezais. O café plantado em Pernambuco suplantou as matas dos brejos e empurrou para áreas de solo mais arenoso as pequenas e tradicionais lavouras, como o milho, feijão e a mandioca.

Conforme Andrade (1961), até a aplicação da política de erradicação dos cafezais, esta zona constituiu-se na principal área produtora de café de Pernambuco. Nesta paisagem, predominava a monocultura e, da antiga Mata Atlântica de Pernambuco, pouco restou, além do substantivo "Mata".

Em Pernambuco, muitos povos que conheciam bem as características da geografia local e tinham uma maneira própria de se prover da natureza, tiveram que fugir e se refugiar em áreas de difícil acesso. A partir da segunda metade do século XIX intensificaram-se as afirmações oficiais do desaparecimento dos índios em Pernambuco e da extinção dos aldeamentos. Essas informações desencontradas começaram a cair por terra com a criação do Movimento Indígena no Brasil, em 1970, período histórico no qual “os indígenas vão paulatinamente aparecendo como os próprios interlocutores na construção de suas demandas e defesa de seus direitos (OLIVEIRA, 2011).

Assim, a imagem dos 'caboclos' substituiu a do indígena, tanto nos discursos como em obras literárias sobre fatos pitorescos, recordações e "estórias" da região Agreste e Sertão pernambucano. Desta forma, podem ser citados escritores e vários estudiosos, como Gilberto Freyre, Estevão Pinto, Câmara Cascudo, dentre outros, que ao valorizar o termo "caboclo", o miscigenado, fortaleceram a alocução do desaparecimento indígena. De acordo com Silva (2017), em 1973, no Estatuto do Índio, foi criada uma lei que visava 'integrar' os povos indígenas à sociedade brasileira, transformando-os em trabalhadores rurais.

O colonizador europeu após usurpar os territórios dos povos originários promoveram o massacre, extinção e escravidão de vários povos. Assim a sociedade e cultura brasileira foi construída de forma etnocêntrica e estereotipada com base em valores hegemônicos, patriarcais, branco, heterossexuais e burgueses. Com relação à construção da imagem histórica dos povos indígenas pelos colonizadores e sociedade moderna, Weigel (2000) salienta que: 
O índio é o outro e um outro inferior, pobre, atrasado e selvagem, "filhos da natureza", que compõem o projeto político do brasileiro apenas como mão-de-obra necessária ao extrativismo, às obras públicas e a produção de farinha de mandioca para abastecer os núcleos urbanos. Nessa forma de conceber, ao branco cabia subordinar, controlar e civilizar os índios (WEIGEL, 2000, p. 94).

A cultura eurocêntrica colonial desvalorizou e invizibilizou todas as demais formas de saberes, modo de vida e de mundo diferente do modelo hegemônico. O processo de subalternização da condição indígena formou uma imagem de subjugação desses povos, em nome da consolidação da dominação ibérica. Assim, a identidade brasileira se constituiu contrapondo-se a identidade indígena (MONTEIRO, 2014, p.31).

Para Boaventura de Souza Santos (2007) o pensamento moderno ocidental é um pensamento abissal. Para o autor esse pensamento "divide a realidade social em dois universos distintos: o deste lado e o do outro lado da linha. A divisão e tal que o do outro lado da linha desaparece como realidade, tornando-se inexistente" (SANTOS 2007, p. 41). A consequência disso é a anulação de outras culturas, ou a impossibilidade mesmo de reconhecimento do valor do outro (ALMEIDA, 2010), como é o caso dos povos indígenas que tem seus direitos, saberes e territórios negados e violados.

O conhecimento hegemônico da sociedade moderna enxerga os povos indígenas como parte do passado do Brasil ou como algo pertencente ao folclore popular e não da população brasileira. No imaginário social foi consolidada uma imagem do indígena como bárbaro, selvagem, povo extinto e atrasado, que não condiz com a realidade.

\section{O ESTADO BRASILEIRO E A VIOLAÇÃO DOS DIREITOS INDÍGENAS DO POVO XUKURU}

Em meados dos anos 1980 o povo Xukuru se mobilizou e participou ativamente dos debates em torno da Assembleia Nacional Constituinte e da elaboração da nova Constituição, no ano de 1988. Ressalta-se a importância ativa do Conselho Indigenista MissionárioRegional Nordeste (CIMI-NE) e da Liderança de Francisco de Assis Araújo, o cacique "Xicão". A região da Serra de Ororubá é marcada por conflitos entre os indígenas e fazendeiros, destacando-se, dentre os "motivos", por estar posicionada em um brejo de altitude, favorecida na sua formação, fazendo com que haja um destaque na produção agrícola local.

A sobrevivência humana nessa região do Semiárido pernambucano está intimamente relacionada a alguns poucos rios perenes que nascem nas serras, bem como aos chamados "brejos de altitudes", espaços de clima ameno nos quais uma elevada 
densidade populacional coexiste com as atividades agrícolas e a pecuária (SILVA, 2008, p.2).

Tal vantagem intensificava as disputas pela produção territorial, atraindo a atenção dos grandes fazendeiros grandes fazendeiros, os quais tinham como principal interesse, a implantação da agropecuária na região e beneficiados pelo lento processo de demarcação do território, substituir por o qual iniciou em 1989, mas a homologação só ocorreu em 2001. Houve tempo suficiente para estes fazendeiros "disseminarem a semente" do agronegócio, um poderoso rival das comunidades indígenas nestes tempos modernos.

O interesse dos latifundiários, aliados à ausência da demarcação total da terra, prolongam os conflitos neste território pela posse da terra. Entre 1992 e 2003, cinco indígenas Xukuru foram mortos diretamente em função da luta pela terra. Uma das vítimas, o cacique Xicão, atuava ativamente contra os agropecuaristas, latifundiários e empresas que invadiam as terras já demarcadas.

Em 20 de maio de 1998, no município de Pesqueira, Francisco de Assis Araújo, o cacique Xicão, foi assassinado com cinco tiros a mando de um fazendeiro local. Após o seu assassinato, ficou estabelecido o dia 20 de maio como marco para o povo Xakuru realizar homenagens póstumas e fortalecerem a luta e identidade étnica do povo.

É, portanto, um ritual político que, por meio da ação simbólica, constrói legitimidade e torna mais firmes as relações entre os próprios Xukuru. Ao mesmo tempo, esse evento cria uma tradição local que através da experiência partilhada dá suporte ao coletivo e auxilia as ações futuras (GODINHO, 2000, p.133).

Como a historiografia dos povos e comunidades tradicionais e a história oficial demonstra, desde o período colonial, que o Estado brasileiro viola os direitos e terras dos povos tradicionais ou é conivente, pois a medida que privilegia os grupos econômicos e/ou latifundiários legitima o processo de usurpação das terras da população originária.

De acordo com Silva e Gonçalves (2017), os Xukuru integram o território ao seu modo de vida, sendo o espaço em que residem visto como parte social, econômica, política, religiosa e familiar dessa comunidade. Assim, o território e a comunidade assumem papéis estruturantes, em que a violação de ambos afeta além da moradia a forma como esses povos se reconhecem, se relacionam e se afirmam diante do espaço externo, ou seja, da alteridade.

Em 1989 foi iniciada uma ação judicial solicitando a retirada de ocupantes não indígenas do território Xukuru. Como o processo de demarcação do território não foi realizado em 2002, o caso foi denunciado à Comissão Interamericana de Direitos Humanos (CIDH). No relatório de mérito do caso, divulgado em julho de 2015, a CIDH concluiu que o 
Estado brasileiro era responsável pelas violações de direitos do povo indígena Xukuru e fez recomendações que não foram cumpridas até hoje.

Em 2017, pela primeira vez na história do país, o Estado brasileiro vira réu na Corte Interamericana de Direitos Humanos pela violência praticada contra o povo Xukuru, resultante de mais de 16 anos de morosidade no processo de demarcação do território. De acordo com os Xukuru, a demora no processo provocou, ao longo dos anos, situações de extrema violência, envolvendo morte e criminalização de suas lideranças que, de vítimas, acabaram sendo tratadas como réus.

Assim, a advogada do Conselho Missionário Indigenista, Caroline Hilgert, durante o julgamento, afirmou que o caso Xukuru revela o "gargalo" da estrutura normativa, apontada nessa Corte pelo próprio perito do Estado, ao destacar que, no sistema atual, mesmo depois do reconhecimento formal, o Estado não exerce a proteção dos povos e de suas terras. Isso significa que a demarcação é um ato declaratório e não demarcatório, como reconhece a Constituição (CIMI, 2017).

Desde a promulgação da Constituição de 1988 o Estado brasileiro vem violando o direito de propriedade coletiva do povo Xukurus de Ororubá. No ano de 2018 os povos indígenas do Brasil e em especial o povo Xucuru, junto com o Conselho Indigenista Missionário (CIMI), Organizações Não Governamentais (ONGs), Justiça Global e o gabinete de assessoria jurídica às organizações Populares tiveram uma grande vitória na causa que corria na justiça há 30 anos.

Decisão considerada histórica a Corte Internacional de Direitos Humanos condena o Estado brasileiro e determina o prazo de 18 meses para pagar uma indenização de US\$ 1 milhão de dólares ( $\mathrm{R}$ \$ 3,26 milhões de reais) ao povo Xukuru.

\begin{abstract}
A ação, que é a primeira na qual o Brasil é condenado por violações contra os direitos dos povos indígenas, foi julgada em 21 de março, na Cidade da Guatemala. O povo Xukuru foi assessorado no processo pelo Conselho Missionário Indigenista (CIMI), pelo Gabinete de Assessoria Jurídica às Organizações Populares (GAJOP) e a Justiça Global. O processo de demarcação do território desse povo, iniciado em 1989, até hoje não foi finalizado, com a retirada de ocupantes não indígenas, assim como a garantia de proteção, o que já levou a assassinatos de indígenas no passado (CIMI-NE, 2018, s/p ${ }^{2}$ ).
\end{abstract}

Para essa conquista na Justiça se tornar mais eficaz, é necessário que o Direito se revele mais atuante na proteção dos povos tradicionais existentes em nosso país. A igualdade

2 Reportagem disponível em: https://www.cimi.org.br/2018/03/estado-brasileiro-e-condenado-pela-corteinteramericana-por-violar-direitos-indigenas/ Acessada em: 20/04/2018. 
perante às leis deve se revestir como um constante combate à prática de discriminações. $\mathrm{O}$ reconhecimento das injustiças sociais construídas ao longo da história e por diferentes protagonistas (Estado, latifundiários, empresários) contra grupos étnico-culturais, deve contribuir para sua proteção, como o caso da comunidade indígena Xukuru.

\section{CONSIDERAÇÕES FINAIS}

Compreendemos ser um desafio romper a lógica neo-extrativista que se estabelece no Brasil, quando esta vem sendo sua principal opção política e econômica ao longo da história. No entanto, é preciso compreender os impactos que ela vem causando, como a invasão de territórios, as chacinas, os desequilíbrios ambientais entre outros.

Estas tensões nos convidam a visibilizar as resistências/'insurgências' ao longo do território brasileiro. A luta dos povos do campo por direito à posse da terra e defesa de seus territórios, não é algo novo. O modo de produção capitalista e os latifundiários concentram a posse da terra e sempre buscaram formas de explorar os bens naturais, a terra e a força de trabalho dos camponeses, trabalhadores rurais e povos que vivem no campo.

$\mathrm{Na}$ atualidade, os conflitos no campo têm aumentado substancialmente, principalmente em áreas de comunidades tradicionais, envolvendo posseiros, indígenas e quilombolas. As terras indígenas são alvos da expansão capitalista, e, nesse sentido, buscamos discutir, mesmo de forma breve, o conflito por terra/território dos indígenas Xukuru no Estado de Pernambuco.

Pela primeira vez na história, uma etnia conseguiu colocar o estado brasileiro no banco dos réus, em uma corte interamericana internacional por crimes e violações dos seus direitos. A mobilização dos povos indígenas no Brasil, e do Povo Xukuru do Ororubá teve como objetivo o reconhecimento da sua identidade étnica e a demarcação e retomada do seu território que foi usurpado pelos latifundiários do agreste e semiárido pernambucano.

Portanto, entendemos que diante do quadro que se apresenta pós-golpe parlamentar de 2016, ainda não é o suficiente, mas acreditamos ser um primeiro passo de mobilização internacional para proteção de nossos povos e comunidades tradicionais. 


\section{REFERÊNCIAS}

ANDRADE, M. C. de. Aspectos geográficos do abastecimento do Recife. Recife: Instituto Joaquim Nabuco de Pesquisas Sociais, 1961 (Relatório de Pesquisa).

ANDRADE, M. C. de. A terra e o homem no Nordeste: contribuição ao estudo da questão agrária no Nordeste. 7 ed. São Paulo: Cortez, 2005.

BRANDÂO, Carlos Rodrigues. A comunidade tradicional. In Cerrado, Gerais, Sertão comunidades tradicionais dos sertões roseanos. Montes Claros: 2010 (Relatório de Pesquisa).

BRASIL. Decreto $\mathbf{n}^{\mathbf{0}}$ 6.040/2007. Brasília: Presidência da República, 07 de fevereiro de 2007. Disponível em: http://www.planalto.gov.br/ccivil_03/_Ato20072010/2007/Decreto/D6040.htm. Acesso em 10/08/2018.

CARNEIRO DA CUNHA, M.; ALMEIDA, M. W. B. Populações tradicionais e conservação ambiental. In: CAPOBIANCO, J. (Org.). Biodiversidade amazônica. Avaliação e ações prioritárias para a conservação, uso sustentável e repartição de benefícios. São Paulo: Estação Liberdade; Instituto Socioambiental, 2001.

CIMI. Conselho Indigenista Missionário Indigenista. Dia histórico para os Xukuru e demais povos indígenas na Corte Interamericana. Brasília: CIMI. Disponível em: http://www.cimi.org.br/site/pt-br/?system=news\&action=read\&id=9172. Acesso em 15/08/2017.

CONSELHO INDIGENISTA MISSIONÁRIO. Brasília: CIMI. Disponível em: https://www.cimi.org.br. Acesso em 20/04/2018.

CPT. Comissão Pastoral Da Terra. Questão Agrária no Brasil, 2014. Disponível em: <http://www.cptnacional.org.br/index.php>. Acesso em: 21/04/2018.

DIEGUES. Antonio Carlos (Org.). Os saberes tradicionais e a biodiversidade no Brasil. São Paulo: NUPAUB; PROBIO-MMA, 2000.

DIEGUES, A. C. A etnoconservação da natureza. In: DIEGUES, A. C. (Org.). Etnoconservação: novos rumos para a proteção da natureza nos trópicos. 2 ed. São Paulo: Hucitec/NUPAUB, 2001.

FILHO, Aderval Costa; MENDES, Ana Beatriz Vianna. Direitos dos povos e comunidades tradicionais. Coordenadoria de Inclusão e Mobilização Sociais (CIMOS) - Ministério Público de Minas Gerais (MPMG). 2014.

GODINHO, Paula. A celebração como mecanismo de reiteração de uma cultura resistente: o caso do Couço (1958-1962). In: Etnográfica: Revista do Centro de Estudos de Antropologia Social. IV (1), p. 130-152, 2000.

\begin{tabular}{lll}
\hline Rapozo e Oliveira, 2018 & ISSN 0104-5490
\end{tabular}


HAESBAERT, Rogério. O Mito da Desterritorialização: do fim dos territórios à multiterritorialidade. Rio de Janeiro: Bertrand Brasil, 2004.

LITTLE Paul E. Territórios sociais e povos tradicionais no Brasil: por uma antropologia da territorialidade. In: Anuário Antropológico/2002-2003. Rio de Janeiro: Tempo Brasileiro, 2003.

Monteiro, Melissa Carvalho Gomes. Amu itá tetama: literatura infantil de autoria indígena como projeto político de (re)construção da imagem histórica e da autoimagem dos povos indígenas do Brasil. Rio de Janeiro: Universidade Católica do Rio de Janeiro, 2014 (Tese do Programa de Pós-Graduação em Serviço Social).

OLIVEIRA, João Pacheco de. A presença indígena no Nordeste: processos de territorialização, modo de reconhecimento e regimes de memórias. Rio de Janeiro, 2011.

SCHMIDT, M. V. C. Etnosilvicultura kaiabi no parque indígena do Xingu: subsídios ao manejo de recursos florestais. São Carlos: UFSCAR, 2001 (Dissertação do Programa de Pós-Graduação da Escola de Engenharia de São Paulo).

SAQUET, Marcos A. Os tempos e os territórios da colonização italiana. Porto Alegre: EST edições, 2003.

RAFFESTIN, Claude. Por uma Geografia do poder. São Paulo: Ática, 1993.

SILVA, Edson. História, memórias e identidade entre os Xucuru do Ororubá. In: Revista Tellus. Campo Grande: UCDB, n. 12, 2007-a.

SILVA, E. Xukuru: memórias e história dos índios da Serra do Ororubá (Pesqueira/PE), 1950-1988. Campinas: UNICAMP, 2008 (Tese do Programa de Pós-Graduação em História Social).

SILVA, E. Xukuru: história e memórias dos “caboclos" da Serra de Ororubá (Pesqueira, PE). In: OLIVEIRA, João Pacheco de. A presença indígena no Nordeste. Rio de Janeiro: 2011.

SILVA, Beatriz Barbosa da. Agricultura como base para a construção da identidade territorial dos Xukuru de Ororubá. Recife: UFPE, 2007-b (Projeto de Iniciação Científica $\mathrm{PIBIC/UFPE/CNPq).}$

SILVA, Beatriz Barbosa da. GONÇALVES, Claudio Ubiratan. Agricultura Xukuru e a construção da identidade territorial no sertão de Pernambuco. VIII Simpósio Internacional de Geografia Agrária e IX Simpósio Nacional de Geografia Agrária

GT 3 - Práticas e conflitos nos territórios dos povos indígenas. ISSN: 1980-4555.2017. In: Anais do VIII Simpósio Internacional de Geografia Agrária e IX Simpósio Nacional de Geografia Agrária. Curitiba: (GT 3 - Práticas e conflitos nos territórios dos povos indígenas).

SANTOS, Milton. A natureza do espaço: Técnica e tempo, razão e emoção. $3^{\text {a }}$ edição, Hucitec, São Paulo, 1999. 
SANTOS, B. S. Para além do pensamento abissal: das linhas globais a uma ecologia de saberes. Novos Estudos, n. 79, p. 71-94, nov. 2007.

TOLEDO, Victor M. Povos/comunidades tradicionais e a biodiversidade. In: LEVIN, S. et. al. (Eds.) Encyclopedia of Biodiversity. Academic Press Instituto de Ecologia. Nome da cidade: UNAM 2001 México. 